\title{
Prediction of Process Parameters That Affecting on Surface Roughness in Multi-Point Forming Process Using ANOVA Algorithm
}

\author{
Tahseen Fadhil Abbas* \\ Khalida kadhim Mansor *** \\ *,**,***Department of Production Engineering and Metallurgy / University of Technology \\ *Email:tfalani@yahoo.com \\ **Email: karim_mohsen@yahoo.com \\ ***Email: kh_ak07@yahoo.com
}

(Received 22 June 2018; accepted 18 October 2018)

https://doi.org/10.22153/kej.2019.10.002

\begin{abstract}
Multipoint forming process is an engineering concept which means that the working surface of the punch and die is produced as hemispherical ends of individual active elements (called pins), where each pin can be independently, vertically displaced using a geometrically reconfigurable die. Several different products can be made without changing tools saved precious production time. Also, the manufacturing of very expensive rigid dies is reduced, and a lot of expenses are saved. But the most important aspects of using such types of equipment are the flexibility of the tooling. This paper presents an experimental investigation of the effect of three main parameters which are blank holder, rubber thickness and forming speed that affect the surface integrity for brass ( $\mathrm{Cu} \mathrm{Zn} \mathrm{65-35)}$ with $0.71 \mathrm{~mm}$ thickness.

This paper focuses on the development of prediction models for estimation of the product quality. Using Analysis of Variance (ANOVA), surface roughness has been modeled. In the development of this predictive model, blank holder, rubber thickness and forming speed have been considered as model parameters. The mean surface roughness (Ra) is used as response parameter to predict the surface roughness of multipoint forming parts. The data required has been generated, compared and evaluated to the proposed models obtained from experiments.

Taguchi algorithm was used to predict the forming parameters (blank holder, rubber thickness and forming speed) on product roughness in forming process of Brass $(\mathrm{Cu} \mathrm{Zn} \mathrm{65-35)}$ based on orthogonal array of L9 and finally ANOVA was used to find the optimum parameters that have effect on the product quality.
\end{abstract}

Keywords: Analysis of variance (ANOVA), Forming Parameters, Multipoint forming process (MPF, Surface Roughness.

\section{Introduction}

Multipoint forming (MPF) is a modern manufacturing technology for three-dimensional sheet metal forming process. The idea of forming die of various shapes has been always attractive as a means of reduction costs of die design, since it would permit design iterations to be rapid and nearly cost Free [1].

The effecting method for manufacturing sheet metal product of $3 \mathrm{D}$ complex shapes is sheet metal forming process. This traditional process use a matched solid die set that forms a cavity into which the sheet is displaced. Sometimes, several sets may be needed to form a sheet metal parts. In this process, to produce different shaped of parts that must be required different dies. The design and manufacturing of punch and dies is a costly work and must rely on the experience of designers and workers. The idea of die forming of variable shape has always been attractive as a means of reducing die design costs [2]. 
A schematic of a multipoint forming process with a blank-holder is shown in figure (1).

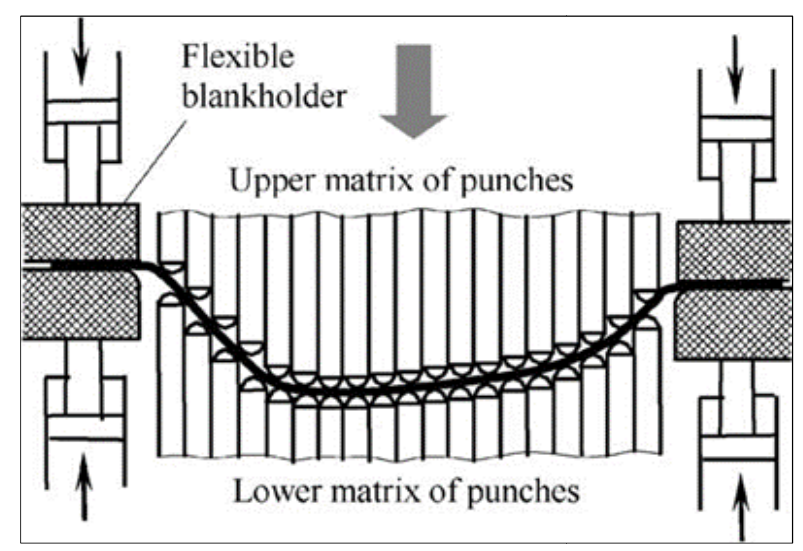

Fig. 1. Principle of multi point forming process [1].

A series of experiment have been carried out in design of experiments to investigate the effect of forming parameters such as blank Holder, rubber thickness and forming speed on surface roughness. Linfa Peng et al (2006) [3] design the contact surface between the workpiece and the surfaces of the blank holder. Two designs were developed to transition surface one is a bridge surface extension, and the flexible surface extension. These two approaches that used continuity type (G2) to transition the design surface with both reliable and effective. In this transition design surface, the Applications gave manufactured the forming product with highquality products in (MPF). Yajie Liu et al (2016) [4] designed an original rigid flexible blank holder (FBH) device. Models of Finite element analysis $(\mathrm{FBH})$ are established without used of blank holder $(\mathrm{NBH})$; the simulation is applying with different $\mathrm{BHF}$ in forming spherical surface parts and then acquired the optimal BHF. The results indicate that $\mathrm{FBH}$ forming process can be release effectively wrinkling defects, thickness distribution is more reasonable, sheet metal flow is more uniform, and distribute uniformly and the stress and strain are minimum. Babak Beglarzadeh (2017) [5] investigate a flexible method for forming a metal, multi-point forming is used to form initial size of $300 \times 300 \mathrm{~mm}$ using aluminum alloy sheet 2024. Finite elements were simulated through ABAQUS/EXPLICIT 6.14.1. Through, increasing of elastic layer (cushion) hardness, the minimum required a thickness of elastic layer proliferates. Furthermore, (BHF) increment has a direct relation with the enhancement in hardness of polyurethane layer. The multipoint forming process of aluminum sheet are performed, and the comparisons of a forming process between simulation functions and experimental parts are applied, which establish that the aluminum products have the best shape accuracy and surface accuracy.

A.A. Tolipov et al (2017) [6] investigated the effect of process variable such as the force of blank holder, elastic cushion thickness, radius of curvature and coefficient of friction on the performance of forming parts in a flexible multipoint process the research was carried out a multipoint forming process using a blank holder in order to study the effects of the, dimpling, wrinkling forming force and reduction of thickness to determine the optimum value of these variables are performed to simulate the multipoint forming of hemispherical shapes using finite element modeling. The effects of process variables on maximum deviation from thickness reduction, the target shape and wrinkling were estimate using the response surface methodology.

Tahseen Fadhel Abaas et al (2018) [7] investigated the achievement of a multipoint die with tools in square matrix and suitable blank holder. Each pin in the punch holder can be a significant moved according to the die high and at different load that applied with spring with respect to spring stiffness. The results shows the reduction in setting time with respect to traditional single point incremental forming process that lead to (90\%). and also show during the forming process, the deformation of the interpolator formed workpiece can induce a shape error and the blank holder can eliminate or reduce dimples in the work-piece.

They predict the optimum value of some process variable that effect on surface roughness and estimate the empirical equation that present the response value with respect to process variables.

\section{Experimental Work 2.1. Material and Process}

Samples of brass alloy ( $\mathrm{Cu} \mathrm{Zn}$ 65-35) with thickness $(0.7 \mathrm{~mm})$ were used to perform the experiments (9-samples). The geometry of forming tool that used in this work is shown in figure (2). While the geometry of final product illustrated in figure (3).

The experimental work was applied using oil lubricant on a C-tek three-axis (KM-80D) CNC machine with rotational speed of $(6000 \mathrm{rpm})$, feed of $(10 \mathrm{~m} / \mathrm{min})$ to manufacturing the hem-spherical shape used as the a half-die. The mechanical 
properties and chemical composition of brass (65$35)$ is illustrated in tables $(1 \& 2)$. The shape of forming tools that used in this work is square tool steel $(15 \times 15 \times 80 \mathrm{~mm})$ while the tip of tool is hem- spherical shape. Three types of blank holder was with different size and shape that illustrated in Figure (4) while multi-point forming die and the final nine products are illustrated in figure (5).

Table 1,

Mechanical properties for Brass sheet (Iso- Cu Zn 65-35 426/1).

\begin{tabular}{|c|c|c|c|c|c|c|c|}
\hline Material & 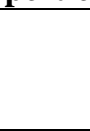 & $\begin{array}{l}\text { Tensile } \\
\text { Strength } \\
\text { MPa }\end{array}$ & $\begin{array}{l}\text { Modulus of } \\
\text { Elasticity } \\
\text { GPa }\end{array}$ & $\begin{array}{l}\text { Poissons } \\
\text { Ratio }\end{array}$ & $\begin{array}{l}\text { Elongation \% on } \\
50 \text { mm G.L. }\end{array}$ & $\begin{array}{l}\text { Vickers } \\
\text { Hardness } \\
\text { HV } \\
\end{array}$ & Iso \\
\hline 65/35 Brass & Exp. & 230 & - & 0.375 & 31.5 & $\leq 100$ & $\mathrm{Cu} Z \mathrm{Zn} 35$ \\
\hline 'O' & Iso & 230 & 110 & 0.33 & 56 & $\leq 90$ & $426 / 1$ \\
\hline
\end{tabular}

Table 2,

Chemical composition of Brass sheet (Iso- Cu Zn 65-35 426/1).

\begin{tabular}{lllllllllllll}
\hline Material & & Zn\% & Pb\% & Sn\% & P\% & Mn\% & Fe\% & Ni\% & Si\% & Al\% & Cu\% \\
\hline \multirow{2}{*}{ Brass } & Exp. & 35.23 & 0.007 & 0.001 & 0.007 & 0.000 & 0.021 & 0.001 & 0.001 & 0.002 & 64.7 \\
& Iso & 35.0 & 0.0 & 0.0 & 0.0 & 0.0 & 0.0 & 0.0 & 0.0 & 0.0 & 65.0 \\
\hline
\end{tabular}
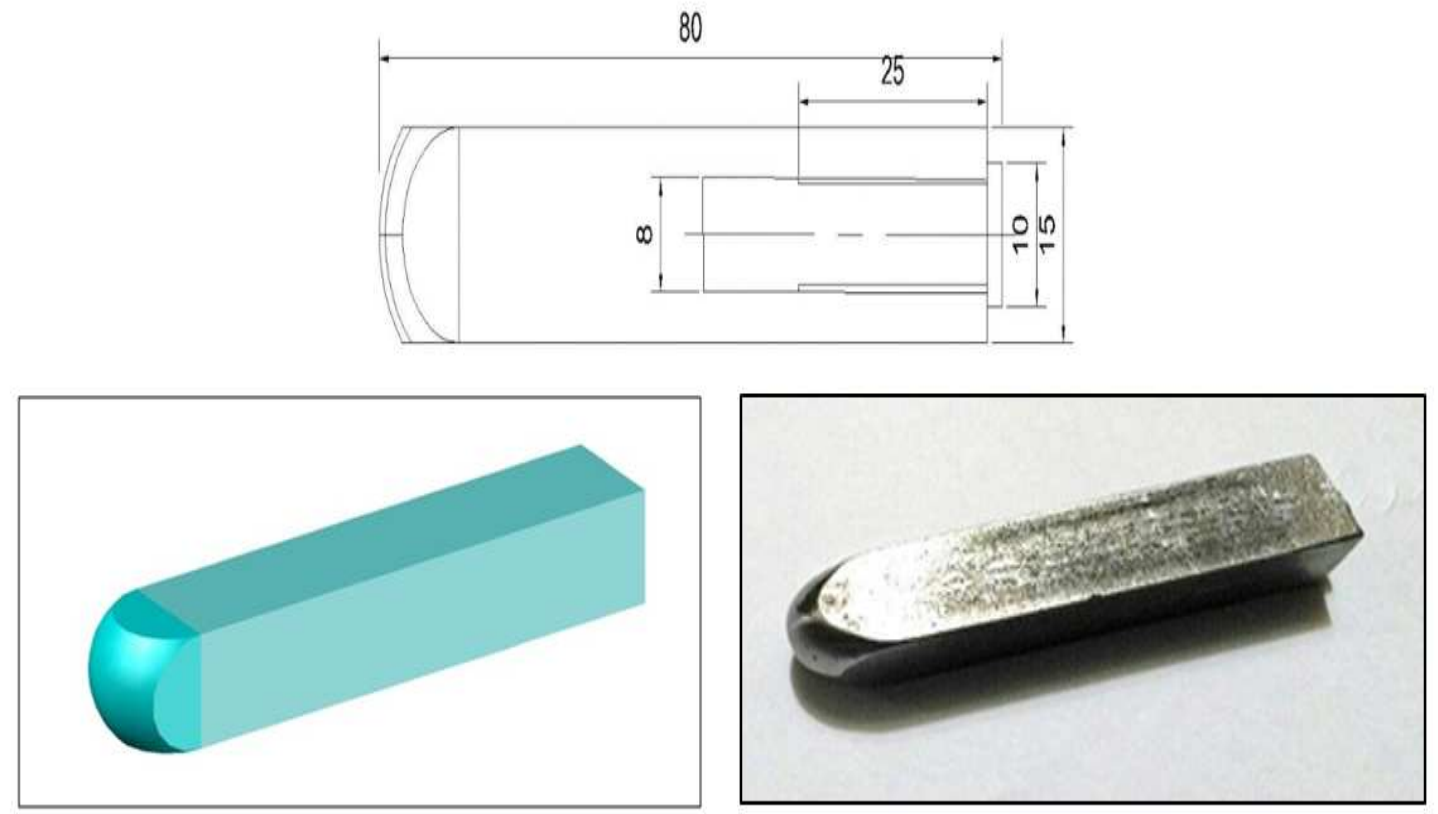

Forming Tool

Fig. 2. Geometry of the forming tool (all dimension in (mm)). 

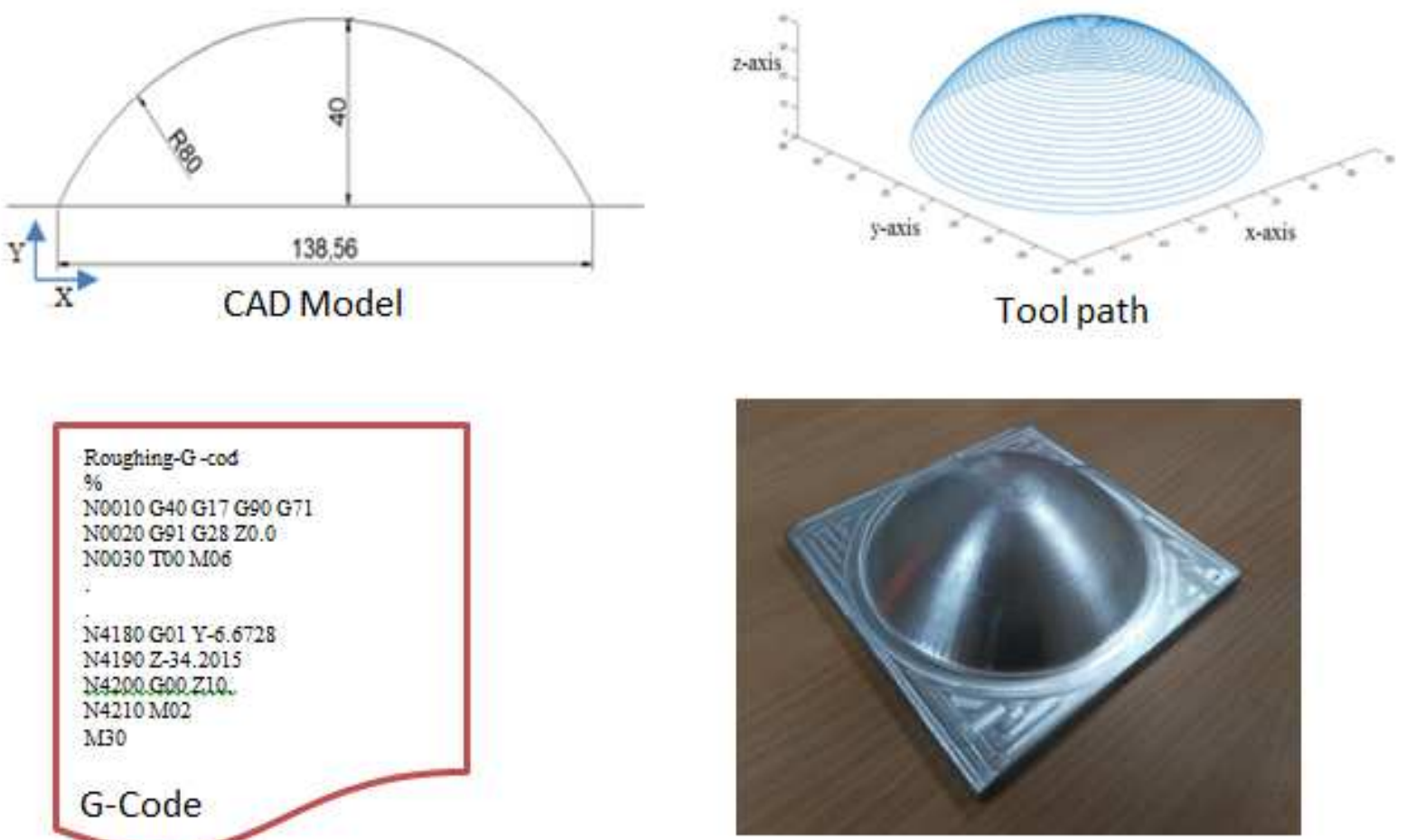

Fig. 3. Geometry of part and CNC-part program. (all dimension in (mm)).
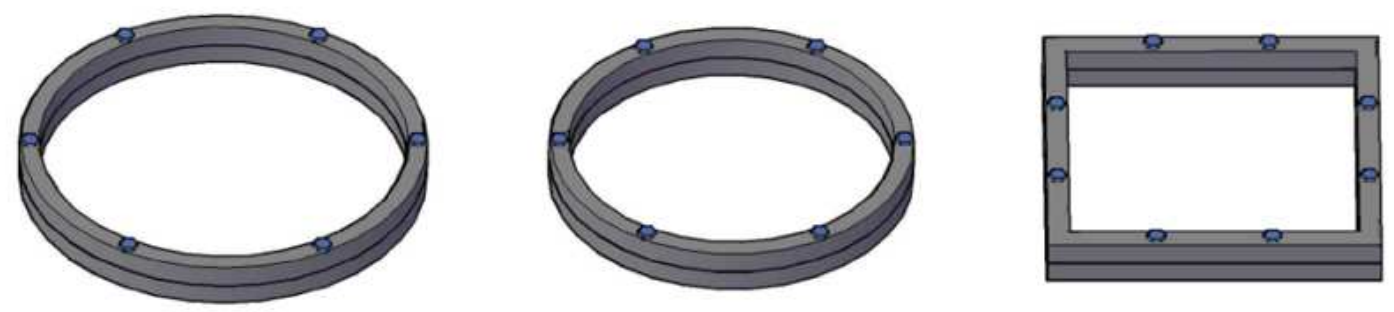

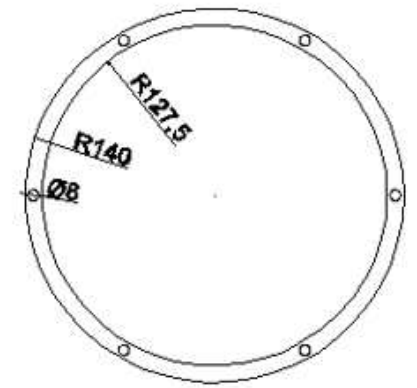

(a)

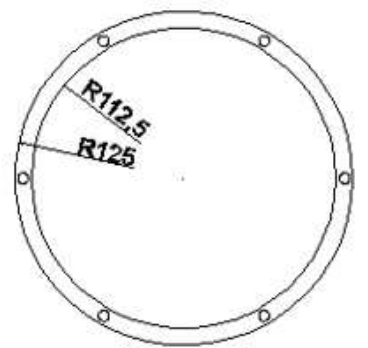

(b)

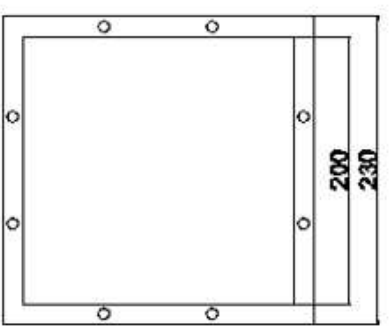

(c)

Fig. 4. Types of blank holder that used in this work. 


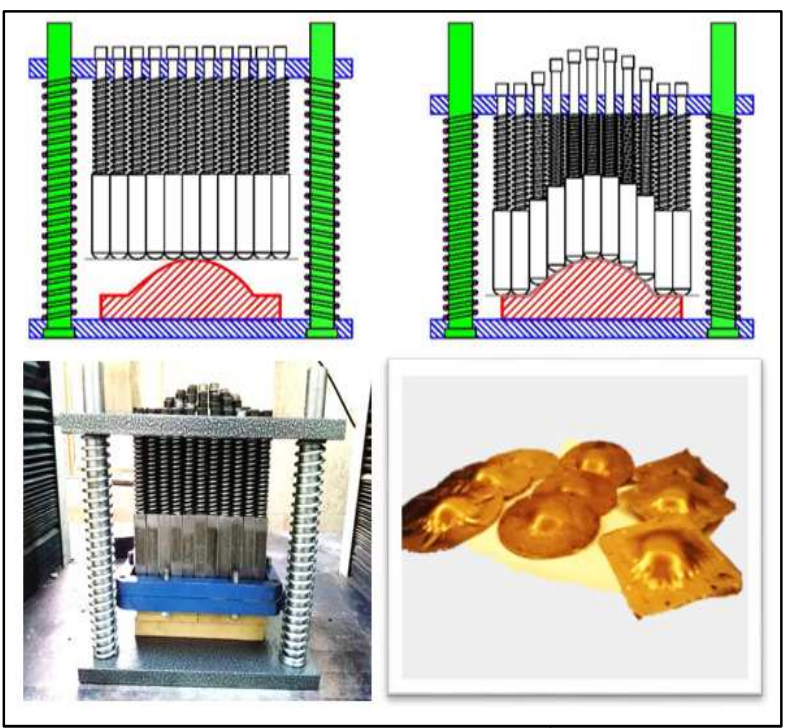

Fig. 5. The experimental setup and nine-samples.

The measurement device that used in this work is surf tester (Mahr pocket surf test) device, figure (6). This device was used to measure the surface roughness of the formed surface, the forming surface was measured after cut off to simplest the measurement procedures at three different positions and Arithmetic mean surface roughness (Ra) are used as output parameters to evaluate the surface quality of multipoint forming product.

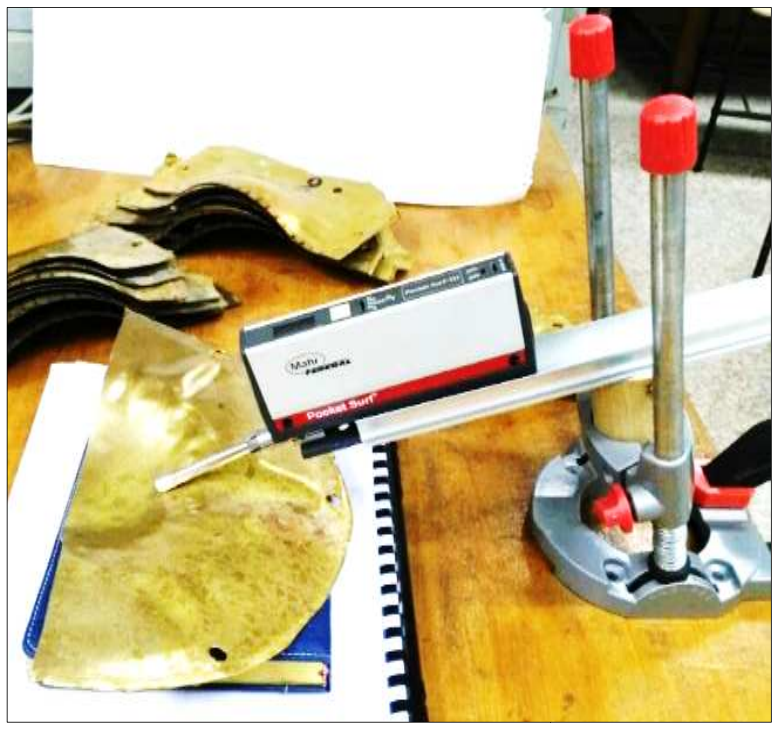

Fig. 6. Surface roughness measurement device.

\subsection{Plan of Experiments}

An important stage in response surface model generation by ANOVA is the planning of experiments. The parameters which has a significant influence on surface quality was identified they by blank holder types, cushion thickness and forming speed in multi-point forming process. Figure (7) present the problem solving and the analysis of data.

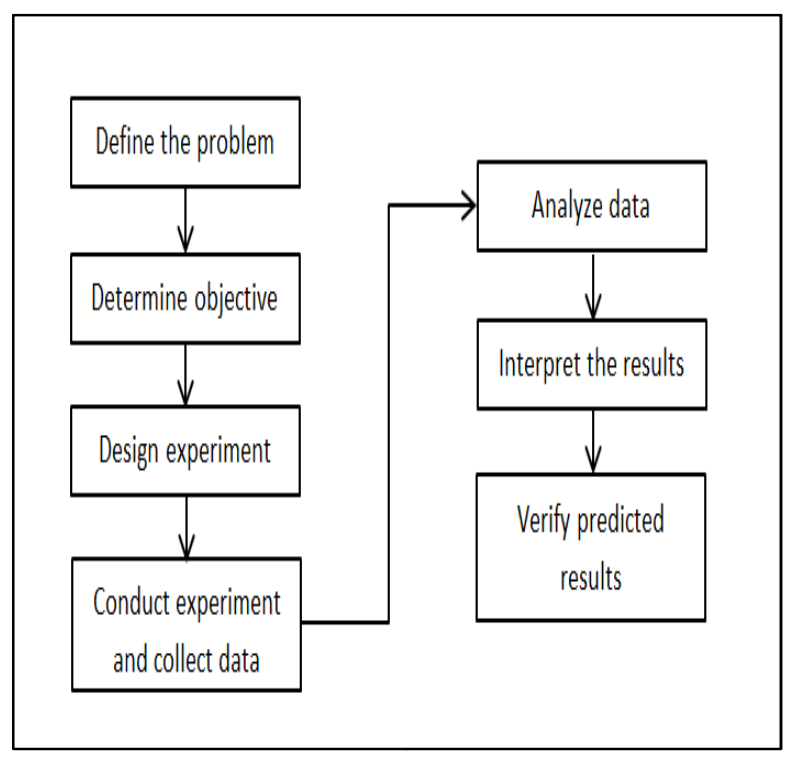

Fig. 7. define the research problem and their analysis.

Uses a special design of orthogonal arrays with a small number of experiments Taguchi method to study the entire parameter space. The methodology of Taguchi for three factors (blank holder, elastic cushion thickness and forming speed) at three levels for each is used to applied the experiments. To define the nine trial conditions, is used the degrees of freedom required for the study is six and Taguchi's (L9) orthogonal array. The levels and process parameters are illustrated in table (3). The average response and Replicated twice values for each of the process designs of nine trials are used. Table (4) illustrated the present work and the test results, and figures $(8,9$ and 10) represent the relationship between experimental data.

Table 3,

levels and parameters

\begin{tabular}{llccc}
\hline Parameters & Unit & Lev.1 & Lev.2 & Lev. 3 \\
\hline $\begin{array}{l}\text { Blank holder } \\
\text { type (B) }\end{array}$ & - & 1 & 2 & 3 \\
$\begin{array}{l}\text { Rubber } \\
\text { thickness(R) }\end{array}$ & $\mathrm{mm}$ & 2 & 4 & 6 \\
\begin{tabular}{l} 
Speed (S) \\
\hline
\end{tabular} & $\mathrm{mm} / \mathrm{min}$ & 2 & 5 & 10 \\
\hline
\end{tabular}


Table 4,

Taguchi's L9 orthogonal array and response value

\begin{tabular}{llllllll}
\hline & Parameters & \multicolumn{5}{l}{ Response value } \\
\hline Exp. No & $\begin{array}{l}\text { blank holder } \\
\text { type }\end{array}$ & $\begin{array}{l}\text { Rubber } \\
\text { thickness } \\
\mathbf{m m}\end{array}$ & $\begin{array}{l}\text { Speed } \\
\mathbf{m m} / \mathbf{m i n}\end{array}$ & $\mathbf{R}_{\mathbf{a} 1}$ & $\mathbf{R}_{\mathbf{a 2}}$ & $\mathbf{R}_{\mathbf{a 3}}$ & $\mathbf{R}_{\mathbf{a v}}$ \\
\hline $\mathbf{1}$ & 1 & 1 & 1 & 1.11 & 1.13 & 1.15 & 1.13 \\
$\mathbf{2}$ & 1 & 2 & 2 & 1.30 & 1.27 & 1.27 & 1.28 \\
$\mathbf{3}$ & 1 & 3 & 3 & 1.02 & 1.09 & 1.06 & 1.0567 \\
$\mathbf{4}$ & 2 & 1 & 2 & 0.50 & 0.58 & 0.57 & 0.55 \\
$\mathbf{5}$ & 2 & 2 & 3 & 0.99 & 1.01 & 1.01 & 1.0033 \\
$\mathbf{6}$ & 2 & 3 & 1 & 1.80 & 1.71 & 1.82 & 1.7767 \\
$\mathbf{7}$ & 3 & 1 & 3 & 0.80 & 0.84 & 0.79 & 0.81 \\
$\mathbf{8}$ & 3 & 2 & 1 & 0.55 & 0.54 & 0.54 & 0.5433 \\
$\mathbf{9}$ & 3 & 3 & 2 & 0.81 & 0.74 & 0.77 & 0.7733 \\
\hline
\end{tabular}

Surface Plot of Average roughness \& blank holder; rubber thickness

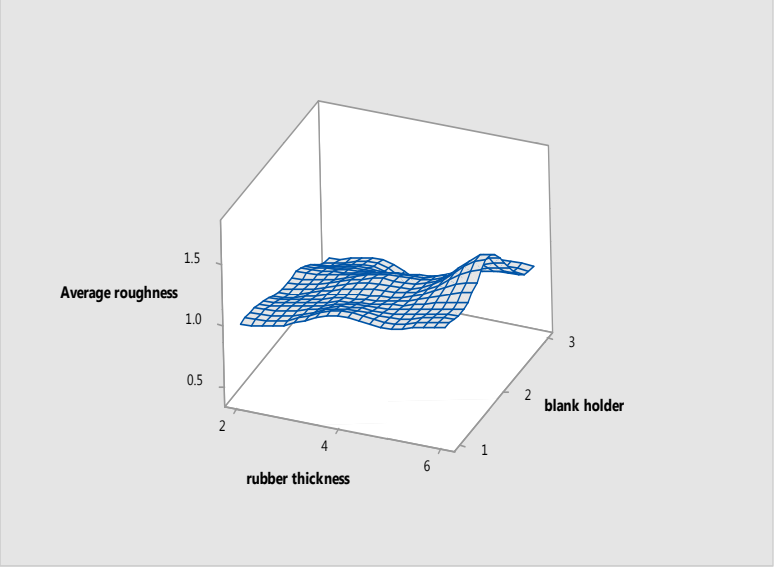

Surface Plot of Average roughness \& rubber thickness; speed

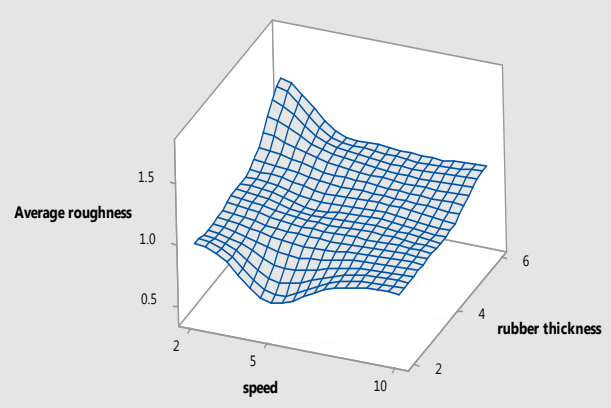

Surface Plot of Average roughness \& blank holder; speed

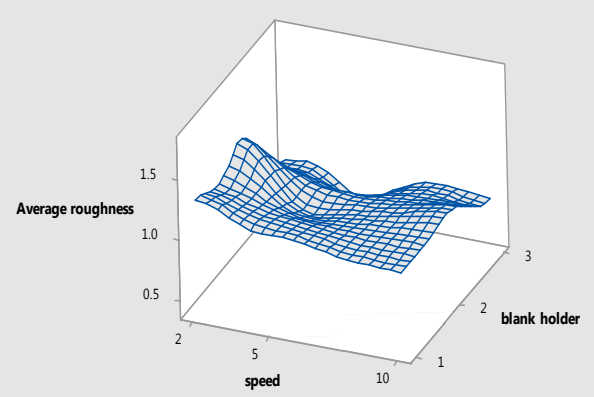

Fig. 8. The relationship of average roughness with respect to process parameters.

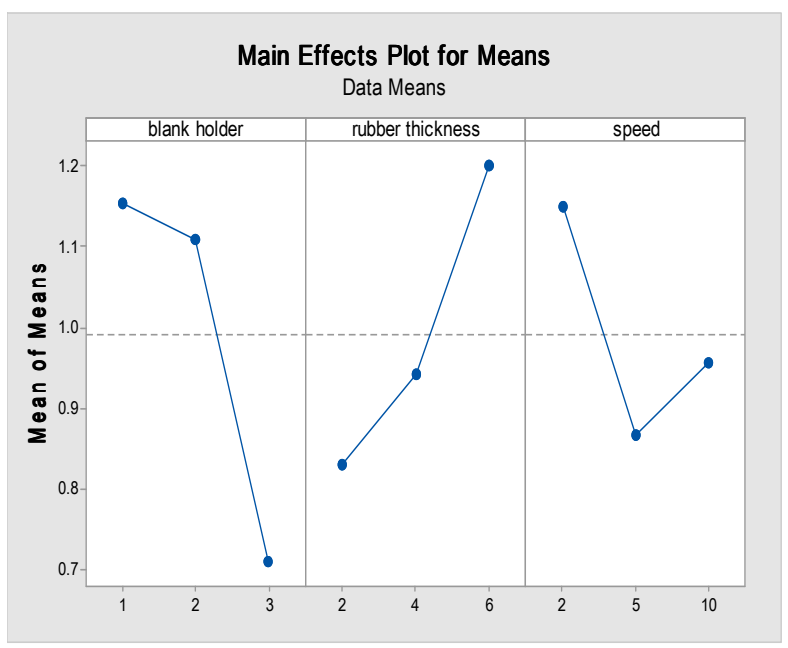

Fig. 9. The relationship of mean of mean for each process variable. 


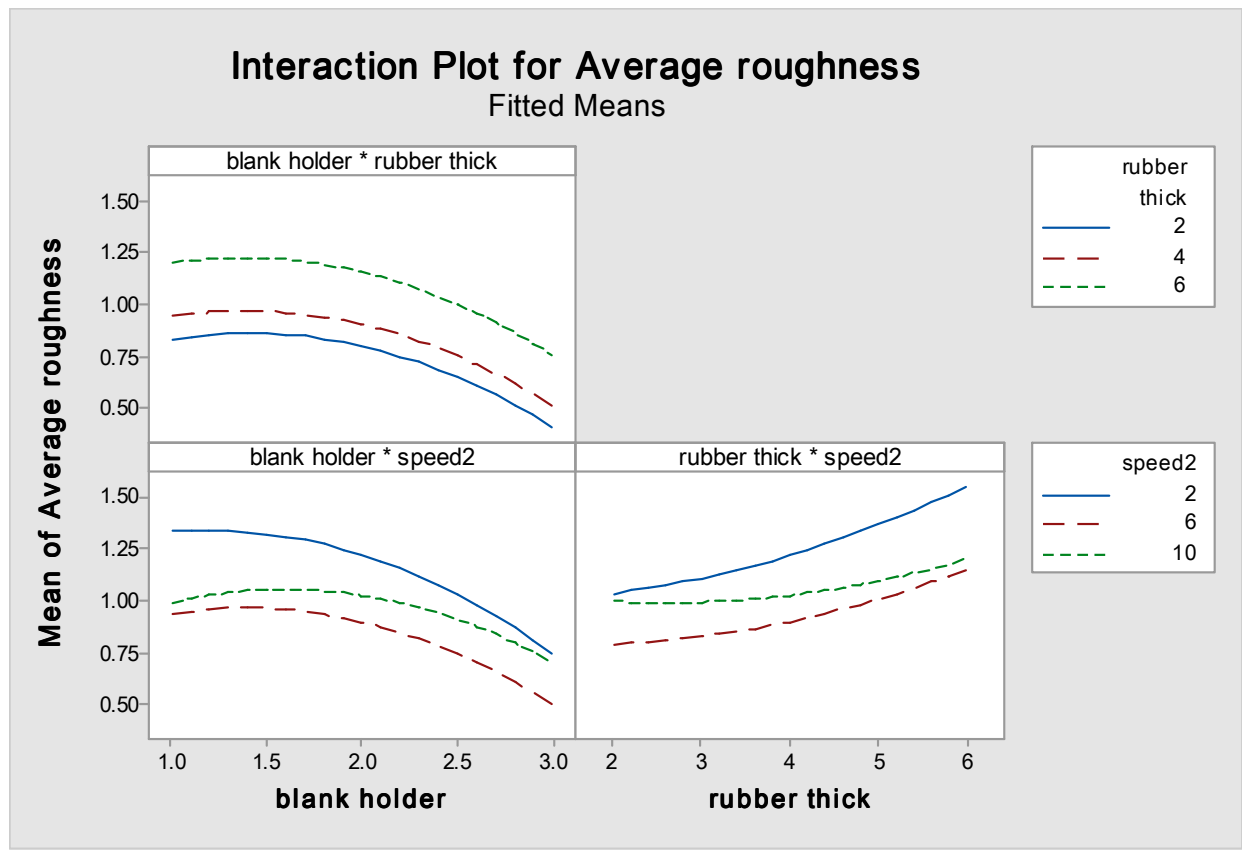

Fig. 10. The relationship of response value with respect to process variables.

\section{Prediction of Process Parameters}

Using Taguchi's algorithm to predict the effect of each parameters on the response value and to estimate the empirical equation contribute between each process parameter in second order as illustrated in equation (1) to optimize the present work with present of confidence $(\mathrm{R}=86.53 \%)$, From the given data (blank holder
(B), rubber thickness $(\mathrm{R})$ and forming speed $(\mathrm{S}))$ with respect to surface roughness. Table (5) represents the final prediction value using Taguchi's algorithm, while table (6) represent the analysis of variance using ANOVA algorithm.

$\mathrm{R}_{\mathrm{av}}=0.5617+0.2034 \mathrm{~B}+0.7165 \mathrm{R}-0.4155 \mathrm{~S}-0.1778$ $\mathrm{B}^{2}-0.03105 \mathrm{R}^{2}+0.0081 \mathrm{~S}^{2}-0.116 \mathrm{BR}+0.1321 \mathrm{BS}$

Table 5,

prediction of process parameters with respect to response value using empirical equation

\begin{tabular}{lllll}
\hline & Process Parameters & & Average Response \\
\hline Exp. No. & blank holder type & Rubber thickness $\mathbf{~ m m}$ & $\begin{array}{l}\text { Speed } \\
\mathbf{m m} / \mathbf{m i n}\end{array}$ & $\begin{array}{l}\text { Surface roughness } \boldsymbol{\mu m} \\
\mathbf{R}_{\mathbf{a v}}\end{array}$ \\
\hline 1 & 1 & 2 & 5 & 0.87037 \\
2 & 1 & 2 & 10 & 0.95925 \\
3 & 1 & 4 & 2 & 1.26481 \\
4 & 1 & 4 & 10 & 1.07148 \\
5 & 1 & 6 & 2 & 1.52481 \\
6 & 1 & 6 & 5 & 1.24259 \\
7 & 2 & 2 & 2 & 1.10704 \\
8 & 2 & 2 & 10 & 0.91370 \\
9 & 2 & 4 & 2 & 1.21926 \\
10 & 2 & 4 & 5 & 0.93703 \\
11 & 2 & 6 & 5 & 1.19704 \\
12 & 2 & 6 & 10 & 1.28593 \\
13 & 3 & 2 & 2 & 0.70592 \\
14 & 3 & 2 & 5 & 0.42370 \\
15 & 3 & 4 & 5 & 0.53592 \\
16 & 3 & 4 & 10 & 0.624815 \\
17 & 3 & 6 & 2 & 1.07815 \\
18 & 3 & 6 & 10 & 0.884815 \\
\hline
\end{tabular}


Table 6,

analysis of variance using ANOVA algorithm

\begin{tabular}{|c|c|c|c|c|c|}
\hline \multicolumn{6}{|c|}{ Analysis of Variance } \\
\hline source & Df & Adj ss & F-Value & P-Value & $\bar{F}$ \\
\hline blank holder & 1 & 0.84043 & 40.61 & 0.000 & $\checkmark$ \\
\hline rubber & 1 & 0.57484 & 27.78 & 0.000 & $\checkmark$ \\
\hline speed & 1 & 0.16820 & 8.13 & 0.011 & $\checkmark$ \\
\hline \multicolumn{6}{|l|}{ Second order } \\
\hline blank $\mathrm{h} *$ blank $\mathrm{h}$ & 1 & 0.18963 & 9.16 & 0.008 & $\checkmark$ \\
\hline rubber*rubber & 1 & 0.03276 & 1.58 & 0.225 & $x$ \\
\hline speed*speed & 1 & 0.25852 & 12.49 & 0.003 & $\checkmark$ \\
\hline \multicolumn{6}{|l|}{ 2-Way Interaction } \\
\hline blank h*rubber & 1 & 0.00038 & 0.02 & 0.893 & $x$ \\
\hline blank h*speed & 1 & 0.06678 & 3.23 & 0.090 & $x$ \\
\hline rubber*speed & 1 & 0.07449 & 3.60 & 0.075 & $x$ \\
\hline Error & 17 & 1.5834 & & & \\
\hline Total & 26 & 2.61191 & & & \\
\hline
\end{tabular}

Level of confidence $(\mathrm{F}$-value $)=95 \%=0.95$

Level of significance $(\mathrm{P}$-value $)=5 \%=0.05$

1- P-value

$\mathrm{P}<0.05 \rightarrow$ Significant

$\mathrm{P}>0.05 \rightarrow$ Non- Significant

2- Fisher value (F-value)

F > FT (from table) Critical tabulated

$\mathrm{FT}=4.4513$

Percent of contribution $\%=\frac{\text { Adj ss }}{\text { Total Adj ss }} * 100 \%$

Percent of contribution \%

Blank holder $=53.075 \%$

Rubber thickness $=36.301 \%$

Speed of forming $=10.622 \%$

\section{Results and Discussion}

The results of this work is to investigate the effect of various forming parameters (blank holder (B), rubber thickness (cushion) (R) and forming speed (S)) with respect to surface roughness that occurs on the forming parts of Brass $(\mathrm{Cu} \mathrm{Zn}$ 65-35) using multi-point forming process. The figures were result from the experimental work using ANOVA algorithm that illustrated in Figures (7and 8). The effects of two input parameters represents in each curve in otherwise the parameter was kept constant.

The effect of blank holder on the minimum surface roughness at the different cushion thickness and forming speed were used. In this work, with respect to the range of forming parameters used, explain that at the rubber thickness $(\mathrm{R}=2 \mathrm{~mm})$ and using blank holder type (3) and forming speed of ( $\mathrm{S}=2 \mathrm{~mm} / \mathrm{min})$ that gives minimum surface roughness $\left(\mathrm{R}_{\mathrm{a}}=0.42370\right)$, as shown in Figures (9) and table (5). While
Figure (10) presents the variance of average roughness value with respect to three process parameters. The final result is estimate the empirical model of each forming parameters with respect to average surface roughness using Taguchi's algorithm. Percentage effect of blank holder types, rubber thickness and forming speed with respect to minimum surface roughness was $(53.075,36.301$ and 10.622$) \%$ respectively as shown in Figure (11).

\section{Percent of contribution \%}

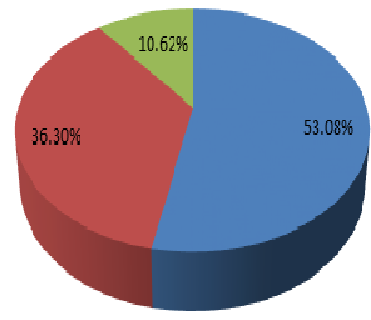

Blank holder

rubber thickness

Forming speed

Fig. 11. The contribution of process parameters that effect on surface roughness.

\section{Conclusion}

The current research reviewed some important aspects related with surface roughness on forming of materials with special emphasis in brass-alloy. Based on the results of the present work of surface roughness in multi-point forming process using ANOVA algorithm, the following conclusions can be drawn: 
1. In multipoint forming process, the process parameters (blank holder types, rubber thickness and forming speed) is the main factors that effect on surface roughness.

2. The results of ANOVA Algorithm and the effectiveness experiments data that the developed empirical models for the output responses provide the predicted values and shows an excellent fit of these surface roughness factors that are close to the experimental values, at $(\mathrm{R}=86.53 \%) \%$ confidence level.

3. The optimum value of roughness that result from this work using ANOVA is equal to $(\mathrm{Ra}=0.42370)$ when using blank holder type (3) and cushion thickness $(\mathrm{R}=2 \mathrm{~mm})$ and at forming speed of $(\mathrm{S}=5 \mathrm{~mm} / \mathrm{min})$.

4. medium forming speed gave the best surface roughness, because it give enough time for the metal to reorganize the atoms and thus reduce the strength of the metal resistance to the forming force, the effectiveness range up to $(10.622 \%)$.

5. Low cushion thickness takes the best surface roughness because the contact area between forming tool and blank is minimum that occurs best result, the effectiveness range up to $(36.301 \%)$

6. The blank holder type (3) gave the best surface roughness up to $(53.075 \%)$.

\section{References}

[1] M.Z. Li, Z.Y. Cai, Z. Sui and Q.G. Yan, Multi-point forming technology for sheet metal, Elsevier Science, Journal of Materials Processing Technology 129 333-338, 2002.

[2] Abdulkareem Jalil Kadhim, and Mostafa Imad Abbas, Three-Dimensional Experimental and Numerical Simulation of
Sheet Metal Forming Process Based on Flexible Multipoint Die, International Journal of Mining, Metallurgy \& Mechanical Engineering (IJMMME) Volume 2, Issue 1, 2014.

[3] Linfa Peng Xinmin Lai, Mingzhe Li, Transition surface design for blank holder in multi-point forming, Elsevier Science, International Journal of Machine Tools \& Manufacture 46, 1336-1342, 2006

[4] Yajie Liu, Mingzhe Li and Feifei Ju, Research on the process of flexible blank holder in multi-point forming for spherical surface parts, Springer, Int J Adv Manuf Technol, 89:2315-2322,2017.

[5] Babak Beglarzadeh, an experimental and numerical study of forming parameters affection on multi-point deep drawing process, International Journal of Advanced and Applied Sciences, 4(1), Pages: 90-95, 2017.

[6] A A Tolipov, A Elghawail, M Abosaf, S Shushing, D Pham and K Essa, Experimental research and numerical optimisation of multi-point sheet metal forming implementation using a solid elastic cushion system, Conference Paper, Department of Mechanical Engineering, School of Engineering, University of Birmingham,UK, July 2017.

[7] Tahseen Fadhel Abaas, Karem Mohsen Younis and Khalida kadhim Mansor, Die Design of Flexible Multi-Point Forming Process, Al-Khwarizmi Engineering Journal, Vol. 14, No.2, June, P.P. 22- 29, 2018. 


\title{
تخمين متغيرات عملية التشكيل متعدد النقاط التي تؤثر على خشونة السطح باستخدام خوارزمية تحليل ألتباين
}

\author{
خالدة كاظم منصور

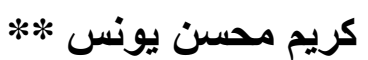 \\ * تحسين فاضل عباس

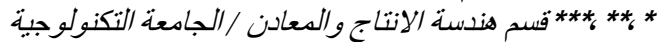

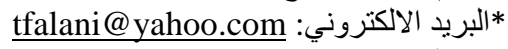 \\ karim_mohsen@yahoo.com البريد الالكتروني الانكروني: ** \\ kh_ak07@yahoo.com البريد الاككتروني:
}

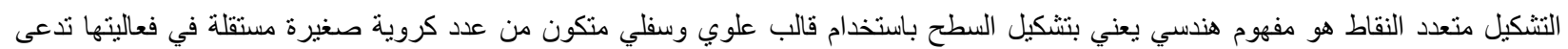

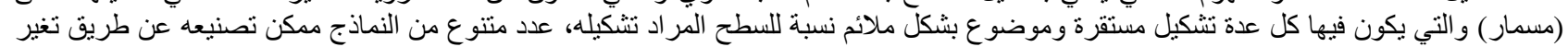

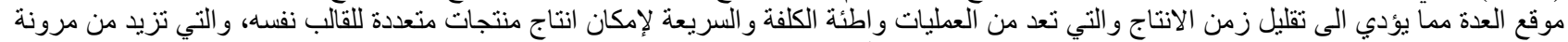

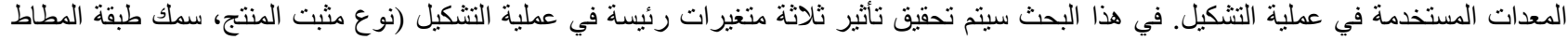

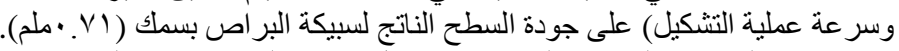

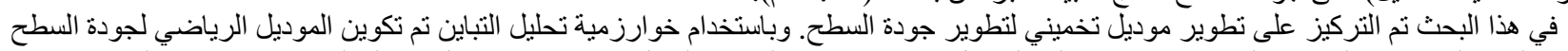

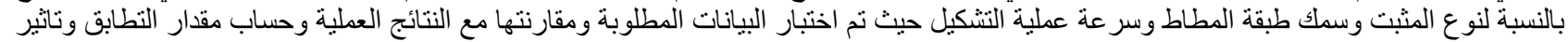

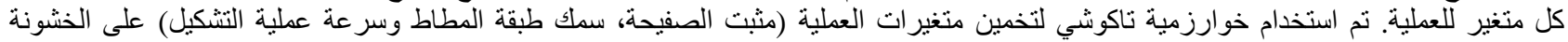

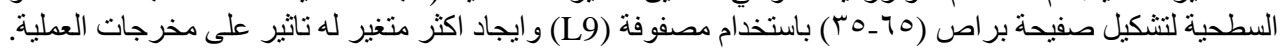

